\title{
O NOVO TITULAR, PROFESSOR REGIS FERNANDES DE OLIVEIRA, PROFERE SEU DISCURSO DE POSSE
}

Senhores,

Como disse Unamuno, em $O$ Segredo da Vida, cada novo amigo que ganhamos, no decorrer da vida, nos aperfeiçoa e enriquece, não tanto pelo que nos dá, quanto pelo que nos revela de nós mesmos.

A amizade com o Professor Geraldo Ataliba já data de muito tempo. Aprofundou-se durante o curso de pós-graduação na Pontificia Universidade Católica. Está arraigada no coração. É amizade desinteressada, mas alicerçada em sólidos laços. De tal ordem que os elogios ficam retratados, à conta dos estreitos vínculos que nos unem. É mais a palavra de amigo, que de professor. Ser saudado por ele é honra reservada a poucos. Suceder Sampaio Dória é outro galardão.

O dia de hoje é muito especial para mim. Quando saí de Monte Aprazivel, em 1963, jamais pensei que fosse ser juiz. Pretendia sê-lo. Desembargador, então nem pensar. Era horizonte muito distante. Presidir os juizes paulistas, brasileiros e latino-americanos era ponto impossível de ser alcançado e não figurava em meus planos. A única pretensão era ser juiz. Entrar, um dia, na Universidade de São Paulo para dar uma aula era expectativa jamais acalentada. Ser professor na Faculdade onde estudaram tantos homens ilustres, poetas notáveis e juristas, que abriram os caminhos do país e que o dirigiram por tantos anos, é honra que recebo com humildade. Sinto-me um anão entre gigantes.

Olho, pasmo, a meu redor e vejo os dignos professores muito de baixo, mirando-os ao alto, com respeito e admiração. Ser dela Professor Titular era sonho impossível.

Entretanto, como diz a música, temos que sonhar o sonho impossivel.

Tudo me foi dado. É muito mais do que sonhava ser. É bênção divina que não merecia. Sinto-me como se entidade superior tivesse feito tudo. Não eu, homem e pó. Nada fiz para merecer tal cargo.

Entretanto, aqui estamos para comemorar a posse nessa Universidade. Desnecessário dizer do meu orgulho. 


\section{Nossa Realidade}

Neste momento, entretanto, devemos realizar uma imersão em nossa sociedade para analisarmos nosso pobre país.

Mergulhado em séria crise social, só não mais agravada dada a passividade de nosso povo, padece o país de terrivel enfermidade. Os coitadinhos, os desvalidos da sorte já não merecem apenas a proteção do Estado. Merecem que o Estado faça por eles as coisas, uma vez que, de tal ordem desprotegidos, não têm decisão própria. A anemia tomou-lhes a vontade. São inermes, são farrapos a desfilar em lamentável alegoria carnavalesca. São fantasmas atrás de alimentação terrena. São corpos ambulantes sem sentido de direção. São bocas famintas. São seios murchos. Tudo a formar dantesca cena de improbidade social.

Ao lado de tal realidade, o luxo insensato. Não se critica a riqueza. Ao contrário, deve ser ela estimulada. $O$ que se analisa são as discrepâncias de renda e a diversidade de possibilidades traçadas pelo País e pelo Governo. É o protecionismo imaturo. É o discurso superado. É a insensibilidade social. É a ausência de compromissos com a sociedade. É a indiferença. É a omissão.

No meio de tais disparidades, um governo apático, anêmico, sem força de vontade para alterar a realidade. Um corpo legislativo, em sua maioria, buscando atender a interesses corporativistas. Um judiciário com estrutura superada e burocratizada.

\section{Universidade}

Quando se depara com a Universidade, vê-se que está distante dos interesses reais do país. As aulas expositivas que pouco transmitem ao aluno. $O$ estudo envernizado a representar casca intelectual. A busca irresponsável pelas notas. $\mathrm{O}$ excesso de alunos por classe. A falsificação das listas. Por que não acabar com elas, se os alunos assinam pelos outros? Apenas para apresentá-las à fiscalização? É a hipocrisia.

O sistema de ensino sucateado por longos anos de irresponsabilidades. Por vencimentos vergonhosos pagos aos professores. Um sistema que privilegia o ensino superior em detrimento do primeiro grau. Um sistema que não atende à Federação, espremendo as universidades estaduais. A 
permanência do credencialismo, ou seja, a busca da nota para passar de ano e a obtenção do diploma.

A repetência de crianças supera os $50 \%$ das matrículas. Somente 45 crianças conseguem concluir o $1^{\circ}$ grau em oito anos. O Brasil tem $14 \%$ de professores leigos ("O Grande Desafio Brasileiro". em Momento Legislativo, n. 31, p. 20, dez. 1993). É verdade, no entanto, que o art. 205 da Constituição da República dispõe que a educação é direito de todos e dever do Estado.

Saúde

Já o sistema de saúde está aquém das necessidades do povo. Construções inúteis. Remédios dominados por oligopólios. Preços absurdos. Falta de leitos. Falta de política adequada. Vencimentos ridículos a médicos e funcionários. Abandono total.

O sistema de saúde é, verdadeiramente, vergonhoso. Diariamente, vêse a população em longas filas, atendimento precário; falta de socorro; corredores onde as pessoas ficam empilhadas. É o triste retrato de um pais, cuja Constituição reza que estamos em estado democrático de direito, tendo como um dos fundamentos a dignidade da pessoa humana (inc. III do art. $1^{\circ}$ ), sendo a saúde direito de todos e dever do Estado (art. 196).

\section{A Distribuição de Renda}

Segundo o livro Distribuição de Renda no Brasil, dos economistas José Márcio Camargo e Fábio Giambiagi, em 1989, os $10 \%$ mais ricos detiveram $52,2 \%$ dos ganhos da população economicamente ativa. A concentração de renda em mãos de um pequeno grupo aumentou. No índice de Gini, que mede a concentração, estamos em 0,63 , quando o máximo da concentração é 1 .

Segundo dados da Organização Internacional do Trabalho, em 1992, no mercado brasileiro, $54,1 \%$ dos trabalhadores urbanos estavam ganhando a vida por conta própria ou realizando o que se denomina "bico" Segundo os mesmos dados, a pobreza aumentou de $41 \%$ em 1980 para $44 \%$ em 1989. A indigência cresceu de $19 \%$ para $21 \%$. Dados do IBGE falam em 32 milhões de brasileiros abaixo do nível de pobreza. 
Relatório do $\mathrm{BRD}$ destaca que o Brasil é o terceiro pior país, do mundo, em matéria de distribuição de renda. Apenas acima de Honduras e Serra Leoa.

Em tal contexto social, não poderia ser o país um ponto importante do mundo. Deixando de lado alguns feitos pessoais, aumenta o distanciamento do povo dos bens de consumo. Se a população não tem dinheiro não consome, criando círculo vicioso na circulação de bens e consumo de alimentos.

Para constatar sermos o país dos contrastes e dos confrontos, perdemos, por mês, de 15 a 20 toneladas de hortifrutigranjeiros (Problemas Brasileiros" n. 297). Perde-se $22 \%$ da produção de arroz; $15 \%$ da de feijão e $10 \%$ da de soja.

Um pais faminto e nababesco, ao mesmo tempo. Um pais pobre e que desperdiça sua produção. Um país rico em minério que não consegue explorar. Um país de terras férteis, mas sem caminhos para a produção e armazenamento. Entretanto, nossa Constituição estabelece que constituem objetivos fundamentais do Brasil a construção de uma sociedade livre, justa e solidária (inc. I do art. $3^{\circ}$ ), ao lado da erradicação da pobreza e da marginalização (inc. IV do art. $8^{\circ}$ ). Além disso a ordem econômica deve atender aos princípios da redução das desigualdades sociais (inc. VII do art. 170).

\section{Violência em Crianças}

Um pais que era jovem e que envelhece, sem qualquer alternativa saudável de vida para jovens e velhos. Segundo dados da Sociedade Internacional de Prevenção ao Abuso e Negligência da Infância, 12\% das 55,6 milhões de crianças brasileiras, com menos de 14 anos sofrem anualmente algum tipo de agressão em sua própria casa ("SOS Criança" in O Estado de S. Paulo, São Paulo, 20 fev. 1994). Por ano, são 6,6 milhões de vítimas da violência, uma média de 18 mil por dia. Somente no Estado de São Paulo, 500 mil crianças sofrem anualmente violência no país. $\mathrm{O}$ que dá a triste média de 1370 por dia. Do número total de agressões, temos que saber que, em 1993, 91\% delas foram praticadas em casa, pelos pais. A triste média de estupro, no próprio lar, atinge $44 \%$ dos casos.

Vê-se, entretanto, a Constituição preceitua, que é dever do Estado assegurar às crianças o direito à vida, à saúde (art. 227), "além de colocá-las a 
salvo de toda forma de negligência, discriminação, exploração, violência, crueldade e opressão"

\section{Comportamento do Jurista}

Neste quadro da nossa realidade social que vimos traçando, qual o papel social do juiz e do professor de direito? Bem se vê a discrepância entre o texto da norma e a realidade, a desconexão entre o mundo normativo e o real.

$\mathrm{O}$ professor não pode conformar-se com tal estado e deve, não apenas informar o aiuno, mas formá-lo. $\mathrm{O}$ aluno de direito tem que ser alguém que olha para sua realidade. Tem que saber que há vida além das salas da Universidade. Não pode, o mestre, ensinar apenas a lição dos Códigos e das Leis, sem apontar-lhes as lições da vida. Não pode o mestre ensinar só o direito escrito, mas o direito vivo. Não pode limitar-se a falar sobre uma realidade que não é a do Brasil. Não podemos fingir que a relação professor-aluno é efetiva, mas fria e distante da realidade; temos que nos conscientizar que nossa realidade é crua. O Brasil é a imagem de um país sacrificado por anos de escravidão, de violência, de contravenção como o jogo do bicho, de corrupção, de falcatruas, de disparidade social. Nosso direito, pois, não pode ser o do primeiro mundo, porque nele nós não estamos. Nosso direito tem que se adaptar à realidade. Não podemos desconhecer a violência nas prisões, mas não podemos ignorar a das ruas. $O$ povo indefeso e sem esperanças.

O juiz vê um Judiciário de estrutura burocratizada; sem autonomia financeira; com servidores mal pagos; distante de seu povo.

Como podemos nos inserir nesta realidade e transformá-la?

O juiz e o jurista têm que ser autores em vez de atores sociais. Chegou o momento de não mais descrever a realidade, o que tentei fazer como juiz. Mas, chego à conclusão, tal como disse em minha carta de despedida do Tribunal de Justiça, que o juiz tem que ser parcial, para poder ser imparcial. A sociedade brasileira é de tal ordem desigual, que o juiz não pode ser imparcial. Tem que ter compromissos com seu povo. $\mathrm{O}$ juiz e o jurista têm, agora, que ser agentes de transformação social. A deusa-símbolo deve ter olhos desvendados para ver a realidade e não ser o bufão da corte, a assinar sentenças cujo conteúdo ignora.

É incongruente? Positivamente não. Não podemos desconhecer nossa realidade crua. Prostituída. Deformada. Agressiva e agredida. 
Diante de tal quadro, proponho que se reforme o país, com base nos princípios éticos, consubstanciados nas seguintes propostas:

\section{a. no Judiciário}

- maior competência aos magistrados para prisão de todos aqueles que foram acusados de desvio de verbas públicas. Aliás, em pesquisa determinada por Mitterrand, na França, para melhorar o Estado, realizada por Blandine Barret Kriegel, a resposta principal foi a de concessão de maior poder ao Judiciário (Jornal Zero Hora, de Porto Alegre, de 03 de junho de 1990).;

- desburocratização do Judiciário com a construção de fóruns democráticos na periferia das grandes cidades, ao lado de aumento da competência dos juizados especiais;

- criação de Tribunais no interior do Estado;

- eliminação dos inúmeros recursos;

- eliminação da burocracia processual, tais como ausência de formalidades na petição inicial, na produção de prova e nos recursos;

- democratização interna, com eleição do Presidente dos Tribunais por todos os juízes.

\section{b. no Legislativo}

- extinção de uma das Casas do Congresso, passando do bicameralismo, para o unicameralismo;

- eliminação da tramitação burocratizada dos projetos;

- controle efetivo sobre o orçamento;

- rigidez de prazos para aprovação dos projetos, à exceção dos Códigos.

Em relação às alterações constitucionais, no que irá operar sobre o Executivo, impõe-se que se redimensione o tamanho do Estado na economia. Não mais pode o Estado intervir, indiscriminadamente, a ponto de tornar-se, quase, o único produtor e distribuidor de riquezas. Deve priorizar os serviços públicos que são segurança, saúde, justiça e ensino. O mais, deve ficar aos particulares, permanecendo o Estado como controlador dos abusos do poder econômico. De igual maneira, deve amparar os desfavorecidos, provocando a igualdade. Em segundo lugar, ponto que se me afigura básico, é a redução dos tributos. Não há mais quem 
os suporte e a toda a carga burocrática. Apenas os denominados tributos com função extrafiscal de controle e também um único que possa ser de pequeno percentual, mas de cobrança obrigatória. Deve ser reajustada a previdência social, para que ela possa cumprir sua função, ao lado da previdência particular, que atenderia com melhor eficiência aos interesses dos servidores.

O enxugamento do Estado imporia a edição de normas para maior eficácia sobre controle interno de fiscalização. O orçamento, como programa de governo, teria seu conteúdo político inapreciável pelo Congresso que aderiria a ele ou o rejeitaria, publicando-se a peça orçamentária como de exclusiva responsabilidade da Chefia do Governo.

Neste exato momento histórico, impõe-se a criação de uma constituinte exclusiva. Teria ela o compromisso de elaborar um texto constitucional atualizado sem compromissos partidários e corporativos. Seus componentes seriam indicados, por segmentos sociais, dentre juristas, economistas, representantes sindicais, patronais e de empregados, enfim, de toda sociedade viva. Entretanto, num gesto de patriotismo e acendrado amor, esqueceriam interesses pessoais e partidários para dotar o País de um instrumento hábil de transformação da sociedade e voltar a seus lares tendo cumprido o dever patriótico. É sonhar? É delirar? Devemos, no entanto, esperar gestos de dignidade, de renúncia e de paixão.

Somente assim é que poderemos construir um outro País, aquele que queremos, não o que temos. O Brasil necessita de reformas estruturais e urgentes.

A modernização, então, do Estado, que seria administrado com competência e efetiva fiscalização. Os mecanismos de controle se impõem, porque a diferença entre a genialidade e a estupidez, é que a genialidade tem limites.

Este é o Estado que se deseja, verdadeira utopia política a fazer sonhar com alguma coisa em que nossos filhos possam viver em segurança e que a fome desapareça de nosso meio, qual sonho de Martin Luther King, o que passa por estado de alegria coletiva entre todos os brasileiros. Com a evolução da economia, o desemprego terá final e o pai de familia poderá voltar com o pão para sua casa. $O$ estudante terá horas de estudo e convivio, para efetiva participação política, o que hoje não tem feito.

Enfim, o problema não é quem vai governar, mas que o governo se exerça através de instituições políticas organizadas e fortes, de tal forma que os 
maus governantes ou os incompetentes possam ser rapidamente destituídos e que as instituições se mantenham, não causando danos intensos à população.

O problema é que o problema é nosso e temos a responsabilidade da não-omissão e de assumirmos o país para preservá-lo dos maus governantes. 